Original article

\title{
Adherence to dietary and fluid restrictions among patients undergoing hemodialysis: An observational study
}

\author{
Harish Beerappa, Ramesh Chandrababu* \\ Manipal College of Nursing, Manipal Academy of Higher Education, Manipal, Karnataka, 576104, India
}

\section{A R T I C L E I N F O}

\section{Keywords:}

Patient adherencee

Diet

Hemodialysis

End-stage renal disease

\begin{abstract}
A B S T R A C T
Aim: The aim of the study was to assess the level of adherence to dietary and fluid restrictions among patients undergoing hemodialysis.

Background: Patients with end-stage renal disease are non-compliant to fluid and dietary restrictions lead to undesirable effect on health.

Methods: The observational study design and 60 samples were adopted. The samples were selected by purposive sampling technique who full fill the inclusion criteria. Self-reported fluid and dietary adherence questionnaire were used to collect the data. Data were analyzed using SPSS software version 16.0.

Results: The study revealed that there was a fair to good adherence level for fluid and dietary restrictions.

Conclusion: However the adherence level varies among hemodialysis patients, individually tailored interven-

tions and constant motivation is needed to improve the adherence level and positive clinical outcome.
\end{abstract}

\section{Introduction}

Chronic kidney disease (CKD) is a global public health problem, the prevalence of End Stage Renal Disease (ESRD) cases are 150 per million and about $9-13 \%$ of patients who are on dialysis die within one year. ${ }^{1}$ The all-cause mortality rate in hemodialysis patients is $6.3-8.2$ times higher than the general population. The most common factors affect the patient survival was pre-dialysis care, inadequacy of dialysis and nonadherence to treatment regimens. ${ }^{2}$ Dialysis patients are a unique patient population in the context of treatment adherence due to a highly complex treatment regimen that concerns multiple facets of their lives; an integration of multiple domains related to dialysis treatment, medication, fluid and diet intake is necessary for optimal disease management and along with lifetime behavioral and social readjustment. ${ }^{3}$

Given this complexity, an assortment of measurement methods, including biochemical markers, patient self-report, together with diverse definitions, have been used to examine non-adherence in dialysis patients. Compliance is a term, which describes when to what extent the patient is consistent with the healthcare recommendations. ${ }^{4}$ Nonadherence is related to client's reluctance to follow the physician's instructions and medical obliviousness. ${ }^{5}$ Some of the qualitative research studies describe that the non-adherence is an indication of clients incapability to incorporate the treatment strategies into their desired lifestyle. ${ }^{5}, 6$

The positive clinical outcome in ESRD patients mainly depends on strict adherence to the therapeutic regimens, even though patients are aware the importance of compliance for sustaining good quality life, many clients fail to adhere to the treatment regimens. ${ }^{7}$ As evident from these selected studies, there is a high degree of variance in non-adherence levels, ranging from 0 to $18 \%$ for missed dialysis sessions, $0-22.4 \%$ for shortened treatment time, $3-80 \%$ for medication, $9.8-75.3 \%$ for fluid intake, and $2-81.4 \%$ for diet restriction. ${ }^{8-13}$

The clinical outcomes are directly depended on the patient's adherence to treatment regimen. If the patient is non-compliant with fluid and diet, leads to increase interdialytic weight gain (IDWG), cardiovascular morbidity and mortality. Excessive dietary sodium intake stimulates osmoreceptors to create a thirst and encourages volume intake, increased total body water and therefore result gain in IDWG. ${ }^{14} \mathrm{Ex}-$ cessive IDWG necessitates more volume removal during hemodialysis. ${ }^{15-18}$ Elevated risk for mortality with relative IDWG $>5.7 \%$ and elevated risk for fluid overload hospitalization with relative IDWG > $4 \% .{ }^{19},{ }^{20}$

Serum phosphorous level which is greater than $5 \mathrm{mg} / \mathrm{dl}$ ( $>1.61 \mathrm{mmol} / \mathrm{L}$ ) is directly related to greater risk of death in hemodialysis patients. ${ }^{21}$ Excessive potassium leads to ventricular arrhythmias and death. ${ }^{22}$ Recent evidence has revealed that more modest elevation ( $>5.5 \mathrm{mEq} / \mathrm{L}$ ) are associated with risk of death, hospitalization and cardiovascular events. ${ }^{23,24}$ The issue of patient adherence is highly consequential due to its proximal adverse impact on disease outcomes and quality of life, and distally healthcare expenditure and

\footnotetext{
* Corresponding author.

E-mail addresses: harishb85@ymail.com (H. Beerappa), ramesh.c@manipal.edu (R. Chandrababu).
} 
effectiveness of health system..$^{25,26}$ The recognition of magnitude the problem and awful consequences in terms of clinical management and health care has led to expanding research interest, the study of adherence in chronic diseases like ESRD remains a justified agenda. The findings of this study will provide an evidence about dietary and fluid adherence of dialysis patients to the health professionals in creating health care policies and to implement appropriate interventions.

\section{Objective}

The objective of the study was to assess the level of adherence to fluid and dietary restrictions among ESRD patients undergoing hemodialysis.

\section{Methods}

\subsection{Study design and participants}

An observational study was conducted with the total of 60 patients between February 2016 and July 2016 in the outpatient dialysis unit of a tertiary care hospital, Karnataka, India. The sample size is calculated using below-mentioned formula according to a similar study ${ }^{31}$ with $80 \%$ power and $5 \%$ error and the minimum sample required for the study is 60 .

Inclusion criteria for study participation were i) patients who were diagnosed with End Stage Renal Disease ii) hemodialysis patients who completed three months of maintenance of hemodialysis. iii) On regular twice a week on hemodialysis for at least three months or more. iv) Age 19 years or older. v) Understand, Speaks Kannada or English language. Exclusion criteria for study participation: i) patients who were not willing to participate in the study. ii) Critically ill patients who cannot able to communicate.

\subsection{Ethical considerations}

The investigation fits into the principles defined in the Declaration of Helsinki (World Medical Association, 2013). The study was reviewed and approved by the Institutional Review and Ethics Committee. A subject information sheet was provided with clear explanation to each study participants and written informed consent was obtained before including them in the study.

\subsection{Instruments}

The study used three different instruments to collect the data. The first instrument was regarding socio-demographic characteristics like age, gender, religion, educational status, diet and source of information pertaining to fluid restriction and dietary advice. Details regarding to co-morbid diseases like diabetes and hypertension and duration of dialysis also were included in the study. The second instrument was beam balance type of weighing scale. The calibration of weighing was done every day before data collection to check its accuracy. The Third instrument was self-reported fluid and dietary adherence questionnaire. It comprised of details regarding urine output (nil, present, sometimes), fluid adherence (adherent/non adherent), dietary salt adherence (adherent/non adherent), number of dialysis sessions per week (twice/ thrice a week) and any medical consequences leads to hospital admission and any supplementary dialysis details. The third instrument was validated by nursing and nephrology experts.

\subsection{Data collection}

The purpose of this research was explained to all the participants and provided with a subject information sheet. After obtaining the written informed consent, the patients completed the self-reported questionnaire of socio-demographic variables and fluid and dietary adherence questionnaire. The data were collected between February 2016 and July 2016. The patients completed the data collection instrument in the dialysis unit of the hospital. Then the weight of the patient was measured by use of calibrated beam balance weighing scale without footwear. The average time is taken by the participants to fill the data collection form varied between 10-15 minutes. IDWG for the fluid adherence was calculated every week of hemodialysis treatment over the observation period by subtracting the post-dialysis weight.

IDWG was calculated by using the below-mentioned formula IDWG = Pre hemodialysis weight - Post hemodialysis weight. Then each sessions IDWG was entered and the sum of IDWG was divided by the number of days over the observational period (90 days) to determine IDWG on each day. Then the IDWG was categorized as $1 \mathrm{~kg}$ / day (good adherence), $1-<2 \mathrm{~kg} /$ day (fair adherence) and $>2 \mathrm{~kg} /$ day (poor adherence). Clinical parameters like serum phosphorous, potassium and calcium values were retrieved from the case sheet of each patient to determine the dietary compliance. No missing values occurred, as all data were collected by only one person (the principal investigator).

\subsection{Data analysis}

The plan for data analysis was developed in consultation with the biostatistician. Descriptive statistics were used to describe the study sample. The frequency, mean and standard deviation was calculated to report the fluid and dietary adherence rates. Biochemical markers of serum potassium, phosphorous, calcium was calculated and categorized to determine the level of adherence rate among the patients. Statistical analysis was done using the SPSS version 16 . The results were summarized using the tables and presented with narrative descriptions. There were no missing data in the statistical analysis.

\section{Results}

A total of sixty patients (male $\mathrm{n}=44,73.3 \%$; female $\mathrm{n}=16$, $26.7 \%$ ) and the mean age of $58.13 \pm 10.61$ years, were participated in the study. The mean duration of dialysis was $46.06 \pm 14.76$. Most of the participants belonged to Hindu religion ( $n=47,78.5 \%$ ), consumes non-vegetarian diet $(n=52,86.7 \%)$. The most common cause of kidney failure was diabetes (58.3\%) and hypertension (41.6\%).

The number of dialysis sessions undergone by the participants in a week was about three times $(n=39,65 \%)$ and only $5 \%$ of the participants were hospitalized and had supplementary dialysis due to fluid overload. Most of the participants reported that they are adherent to salt restriction $(n=47,78.3 \%)$ and regular to dialysis session $(n=54$, $90 \%$ ) and only $8.3 \%$ and $1.6 \%$ of them have missed out one and two dialysis session respectively. (Tables 1 and 2).

Level of fluid adherence: most of the participants $(n=31,51.6 \%)$ are fair adherence to fluid restrictions (1- $<2 \mathrm{~kg} /$ day) with a mean weight of $1.27 \pm 0.19 \mathrm{~kg}$ /day, poor adherence $>2 \mathrm{~kg} /$ day $(\mathrm{n}=1$, $1.6 \%)$ and good adherence $<1 \mathrm{~kg} /$ day $(\mathrm{n}=28,46.6 \%)$ with a mean weight gain per day was $0.7 \pm 0.22 \mathrm{~kg}$. The total mean interdialytic weight gain of the participants was $1.40 \pm 0.37 \mathrm{~kg} /$ day. This indicates that overall there is a moderate adherence to fluid restrictions among the participants (Table 3).

Level of dietary adherence: it was found that most of the participant's serum phosphate level was in the range of $2.5-4.5 \mathrm{mg} / \mathrm{dL}$ $(\mathrm{n}=41,68.3 \%)$ with mean $3.27 \pm 0.98 \mathrm{mg} / \mathrm{dL}$ indicates good adherence. $20 \%$ of the participants were fair adherent to dietary phosphorous (4.6-6.0 mg/dL) with a mean $4.8 \pm 0.26 \mathrm{mg} / \mathrm{dL}$ and poor adherence (serum phosphorous $>6 \mathrm{mg} / \mathrm{dL}$ ) is $11.7 \%$ with a mean $7.0 \pm 1.5 \mathrm{mg} / \mathrm{dL}$. The mean pre hemodialysis serum phosphorous level is $4.25 \pm 1.4 \mathrm{mg} / \mathrm{dL}$, it shows moderate adherence to dietary phosphorous level. Only ( $n=17,28.3 \%)$ participants are prescribed with phosphate binders and they reported that they are adherent to phosphate binders (Table 3). 
Table 1

Socio-demographic data of the study participants.

\begin{tabular}{llll}
\hline \multirow{2}{*}{ Demographic characteristics } & Frequency & Percentage & \\
\hline \multirow{2}{*}{ Gender } & Female & 16 & 26.7 \\
& Male & 44 & 73.3 \\
Religion & Hindu & 47 & 78.3 \\
& Christian & 08 & 13.3 \\
& Muslim & 05 & 8.3 \\
Diet & Non- & 52 & 86.7 \\
& vegetarian & & \\
& Vegetarian & 08 & 13.3 \\
Education & Formal & 56 & 93.3 \\
& Informal & 04 & 6.7 \\
Source of information & Doctor & 56 & 93.3 \\
(dietary and Fluid advice) & Dietitian & 04 & 6.7 \\
Comorbid & Diabetes & 35 & 58.3 \\
disease & Hypertension & 25 & 41.6 \\
\hline
\end{tabular}

Table 2

Self-reported behaviours on dietary and fluid adherence among the study participants Add hyphen in Non-adherence in all the places.

\begin{tabular}{|c|c|c|c|}
\hline \multirow{3}{*}{$\begin{array}{l}\text { Components } \\
\text { Number of dialysis sessions/week }\end{array}$} & \multirow{3}{*}{$\begin{array}{l}\text { Frequency } \\
\text { Twice } \\
\text { Thrice }\end{array}$} & \multicolumn{2}{|c|}{$\begin{array}{l}\qquad(n=60) \\
\text { Percentage }\end{array}$} \\
\hline & & 21 & 35 \\
\hline & & 39 & 65 \\
\hline Medical consequences & Yes & 03 & 5.0 \\
\hline $\begin{array}{l}\text { (Emergency visit and Supplementary } \\
\text { dialysis) }\end{array}$ & No & 57 & 95 \\
\hline \multirow[t]{2}{*}{ Salt restriction } & Adherence & 47 & 78.3 \\
\hline & Non adherence & 13 & 21.7 \\
\hline \multirow[t]{2}{*}{ Fluid adherence } & Adherence & 17 & 28.3 \\
\hline & Non adherence & 43 & 71.7 \\
\hline \multirow[t]{3}{*}{ Urine output } & Yes & 12 & 20 \\
\hline & No & 42 & 70 \\
\hline & Sometimes & 06 & 10 \\
\hline \multirow[t]{3}{*}{ Attendance to dialysis ( 3 months) } & $\begin{array}{l}\text { Not missed any dialysis } \\
\text { session }\end{array}$ & 54 & 90 \\
\hline & $\begin{array}{l}\text { Missed out } 1 \text { dialysis } \\
\text { session }\end{array}$ & 05 & 8.3 \\
\hline & $\begin{array}{l}\text { Missed out } 2 \text { dialysis } \\
\text { session }\end{array}$ & 01 & 1.6 \\
\hline
\end{tabular}

Most of the participants $(n=39,65 \%)$ are found to be good adherence to dietary potassium $(3.5-5 \mathrm{mEq} / \mathrm{L})$ with mean value of $4.4 \pm 0.61 \mathrm{mEq} / \mathrm{L}$, fair adherence $\left(k{ }^{+} 5.1-6.0 \mathrm{mEq} / \mathrm{L}\right)$ mean $5.3 \pm 0.28 \mathrm{mEq} / \mathrm{L}$, poor adherence $\left(k^{+}>6.0 \mathrm{mEq} / \mathrm{L}\right)$ mean $6.7 \pm 0.13$. Mean pre HD serum potassium level is $5.0 \pm 0.76 \mathrm{mEq} / \mathrm{L}$. Mean pre HD serum calcium level was $9.03 \pm 0.6 \mathrm{mg} / \mathrm{dL}$. There is a moderate adherence to fluid and dietary restrictions based on the statistical analysis of the study.

\section{Discussion}

The current study was conducted to describe the level of adherence behaviours in patients with maintenance hemodialysis and also to assess the association between adherence behaviours with variables among the patients with maintenance hemodialysis. Alternative measures have to identify to improve the fluid compliance behaviour due to its high risk of cardiovascular morbidity and mortality, as it is one of the most challenging tasks.

As the ESRD cannot be reversible, renal transplant is not affordable, raising ESRD patients in the developed and developing countries with
Table 3

Level of dietary and fluid adherence among the study participants.

\begin{tabular}{|c|c|c|c|c|c|}
\hline $\begin{array}{l}\text { Dichotomization: } \\
\text { Adherence /Non- } \\
\text { adherence }\end{array}$ & $f$ & $\%$ & Mean & SD & $(n=60)$ \\
\hline \multicolumn{6}{|c|}{ Fluid adherence level: Interdialytic weight gain } \\
\hline Good Adherence: & IDWG $<1 \mathrm{~kg} /$ day & 28 & 46.6 & 0.7 & 0.22 \\
\hline Fair Adherence: & IDWG $1-<2 \mathrm{~kg} /$ day & 31 & 51.6 & 1.27 & 0.19 \\
\hline Poor Adherence: & IDWG $>2 \mathrm{~kg} /$ day & 01 & 1.6 & & \\
\hline $\begin{array}{l}\text { Mean IDWG (kg/day) } \\
\text { Dietary adherence } \\
\text { Serum phosphorous leve }\end{array}$ & & & & 1.40 & 0.37 \\
\hline $\begin{array}{l}\text { Good Adherence: Serum } \\
\text { dL }\end{array}$ & phosphorous $2.5-4.5 \mathrm{mg}$ / & 41 & 68.3 & 3.27 & 0.98 \\
\hline Fair Adherence mg/dL: & $\begin{array}{l}\text { Serum phosphorous } \\
4.6-6.0\end{array}$ & 12 & 20.0 & 4.8 & 0.26 \\
\hline Poor Adherence: & $\begin{array}{l}\text { Serum } \\
\text { phosphorous }>6 \mathrm{mg} / \mathrm{dL}\end{array}$ & 07 & 11.7 & 7.0 & 1.5 \\
\hline Mean pre HD serum pho & sphorous level & & & 4.25 & 1.4 \\
\hline Number of Patient is on & phosphate binders & 17 & 28.3 & & \\
\hline Number of Patient is no & on phosphate binders & 43 & 71.7 & & \\
\hline \multicolumn{6}{|l|}{ Serum potassium level } \\
\hline Good Adherence: serum & potassium $3.5-5 \mathrm{mEq} / \mathrm{L}$ & 39 & 65 & 4.4 & 0.61 \\
\hline Fair Adherence: & $\begin{array}{l}\text { serum potassium } \\
5.1-6.0 \mathrm{mEq} / \mathrm{L}\end{array}$ & 18 & 30 & 5.3 & 0.28 \\
\hline Poor Adherence: & $\begin{array}{l}\text { serum } \\
\text { potassium }>6 \mathrm{mEq} / \mathrm{L}\end{array}$ & 03 & 05 & 6.7 & 0.13 \\
\hline
\end{tabular}

all the above reasons, the patient must be compliant to certain compliant behaviours for a better quality of life. Patient and family education regarding non-compliant behaviors and its consequences which may bring down the non-adherence rate.

Our study is in line with the previous study conducted on dialysis outcomes and practice pattern are used the variables like skipping of more than one dialysis session, serum potassium level $>6.0 \mathrm{mEq} / \mathrm{L}$, phosphate concentration $>4.5 \mathrm{mg} / \mathrm{dl}$ or IDWG used as measures for non-adherence. ${ }^{27}$ In the current study, the adherence rate was $46.6 \%$ (good adherence), $51.6 \%$ (fair adherence) for fluid restrictions, $60-68.3 \%$ good adherence, $20-30 \%$ fair adherence for dietary restrictions.

The previous studies reported the compliance rate as fluid and dietary restrictions, medications and regular to dialysis sessions from $96.6 \%$ to $26 \%, 98.8 \%$ to $17.6 \%, 98.8 \%$ to $19 \%$ and $100 \%$ to $67.7 \%$ respectively. ${ }^{28},{ }^{29} \mathrm{~A}$ previous research study reported that many patients had difficulty following the diet (81.4\%) and fluid (74.6\%) restrictions. Younger male patients and smokers were at highest risk for non-adherence. Higher levels of IDWG were associated with nonadherence. ${ }^{30}$

Our study results suggest that the routine evaluation of fluid and diet adherence among patients undergoing hemodialysis is necessary with an additional exploration of the consequence of non-adherence. There is a requirement for additional research in this area, along with the development of newer interventions for the patients in improving adherence and promoting health among these patients. Well-designed randomized controlled trials also can be conducted on fluid and diet adherence in order to generate useful interventions for the evidencebased practice.

\subsection{Strength and limitations}

This study has evaluated the fluid and dietary adherence among patients subjected to hemodialysis. Recruitment of the samples was successful as none of the patients resisted to participate in the study and also there were no missing data. This study had addressed the needs of education, counselling and constant motivation on diet and fluid adherence. Some of the limitations existed in this study are noteworthy. Particularly, the representation of a small number of patients of who 
underwent hemodialysis included in the current study and data collection was conducted in a single setting. Therefore, the results of this current study may not represent the larger population of patients undergoing hemodialysis comparing to the previous study. ${ }^{30}$ Generalization of this findings should be done with caution as it was a single setting study. It must be noted that the assessment of diet and fluid adherence was done by a self-reported instrument.

\subsection{Implications of the study}

Monthly compliance progress report can be initiated in the hospital by the dialysis nurse to discuss their patient's non-adherence behaviours. If not compliant with certain behaviours, possible solution, motivation and counselling sessions can be arranged. It's an ongoing process where constant monitoring is required to improve the clinical outcome. Self-help groups help to discuss their common problem in non-compliance behaviours and how to tackle their problems with their personal experience gives an alternate approach for the patients. Interventional studies can be conducted to improve the clinical outcome of compliance behaviours.

\section{Conclusion}

In conclusion, overall the ESRD patients undergoing hemodialysis are fair to good adherence to fluid, dietary and dialysis session, however, the adherence level varies among hemodialysis patients. Individually tailored interventions are needed to improve the adherence level and positive clinical outcome. Effective education, periodic counselling and constant motivation can improve patient's confidence in fluid and dietary adherence to lead a healthy life.

\section{Funding}

The authors have received no funding from any source for this research project.

\section{Conflict of interest}

The authors declared no potential conflicts of interest with respect to the research, authorship, and/or publication of this article.

\section{References}

1. Chandrashekar A, Ramakrishnan S, Rangarajan D. Survival analysis of patients on maintenance hemodialysis. Indian J Nephrol. 2014;24(4):206-213.

2. Collins AJ, Foley RN, Herzog C, Chavers B. US renal data system 2012 annual data report (cl-476). Am J Kidney Dis. 2013;61:A7.

3. Braun Curtin R, Mapes D, Schatell D, Burrows-Hudson S. Self- management in patients with end stage renal disease: exploring domains and dimensions. Nephrol Nurs J. 2005;32(4):389-395

4. Berg J, Evangelista LS, Carruthers D, Dunbar-Jacob JM. Compliance. In: Lubkin IM, Larsen PD, eds. Chronic illness: impact and interventions. Sudbury, MA: Jones and Bartlett Publishers; 2006:221-252.

5. Hill-Briggs F. Problem-solving in diabetes self-management: a model of chronic illness self- management behavior. Ann Behav Med. 2003;25(3):182-193.

6. Krespi R, Bone M, Ahmad R, Worthington B, Salmon P. Hemodialysis patient's beliefs about renal failure and its treatment. Patient Educ Couns. 2004:53:189-196.
7. Denhaerynck K, Manhaeve D, Dobbels F, Garzoni D, Nolte C, De Geest S. Prevalence and consequences of non-adherence to hemodialysis regimens. Am J Crit Care 2007;16(3):222-235.

8. Bleyer AJ, Hylander B, Sudo H, Nomoto Y, Chen RA, Burkart JM. An international study of patient compliance with hemodialysis. J Am Med Assoc. 1999;281(13):1211-1213.

9. Block GA, Hulbert-Shearon TE, Levin NW, Port FK. Association of serum phosphorus and calcium $\mathrm{x}$ phosphate product with mortality risk in chronic hemodialysis patients: a national study. Am J Kidney Dis. 1998;31(4):607-617.

10. Durose CL, Holdsworth M, Watson V, Przygrodzka F. Knowledge of dietary restrictions and the medical consequences of non-compliance by patients on hemodialysis are not predictive of dietary compliance. J Am Diet Assoc. 2004;104(1):35-41.

11. Hecking E, Bragg-Gresham JL, Rayner HC, Lützén K, Clyne N. Haemodialysis prescription, adherence and nutritional indicators in five European countries: results from the dialysis outcomes and practice patterns study (DOPPS). Nephrol Dial Transplant. 2004;19(1):100-107.

12. Leggat JE, Orzol SM, HulbertShearon TE, Golper TA, Jones CA, Held PJ, Port FK. Noncompliance in hemodialysis: predictors and survival analysis. Am J Kidney Dis. 1998;32(1):139-145.

13. Sherman RA, Cody RP, Matera JJ, Rogers ME, Solanchick JC. Interdialytic weight gain and nutritional parameters in chronic hemodialysis patients. Am J Kidney Dis. 1994;24:921-923.

14. Abeculo GJ. Large interdialytic weight gains: causes, consequences, and corrective measures. Semin Dial. 2007;11(1):25-32.

15. Stiller S, Bonnie-Schorn A, Grassman I, Uhkenbusch-Koerwer H. A critical review of sodium profiling for hemodialysis. Semin Dial. 2001;14(5):337-347.

16. Olone EL, Visser A, Finney H, et al. Clinical significance of multi-frequency bioimpendance spectroscopy in peritoneal dialysis patients: independent predictor of patient survival. Nephrol Dial Transplant. 2014;29:1430-1437.

17. Chazot C, Wabel P, Chamney P, et al. Importance of normohydration for the long term survival of hemodialysis patients. Nephrol Dial Transplant. 2012;27(6):2404-2410

18. Hur E, Usta M, Toz H, et al. Effect of fluid management guided by bio impendence spectroscopy on cardiovascular parameters in hemodialysis patients: a randomized controlled trial. Am J Kidney Dis. 2013;61(6):957-965.

19. Michelle Wong MY, Keith Mc Cullough P, Brian Bieber A, et al. Interdialystic weight gain: trends, predictors, and associated outcomes in the International dialysis out comes and practice pattern study(DOPPS). Am J Kidney Dis. 2017;69(3):367-379.

20. Arnson TJ, Liu J, OiuY, et al. Hospital treatment for fluid overload in the medicare hemodialysis population. Clin J Am Soc Nephrol. 2010;5(6):1054-1063.

21. Rodriguez-benot Alberto, Martin-Malo Alejandro, Antonia Alvarez-Lara M, et al. Mild hyperphosphatemia and mortality in hemodialysis patients. Am J Kidney Dis. 2005;46(1):68-77.

22. McDonald TJ, Oram RA, Vaidya B. Investigating hyperkalaemia in adults. BMJ. 2015:351 h4762.

23. Sarafidis PA, Blacklock, Wood E, et al. Prevalence and factors associated with hyperkalemia in predialysis patients followed in a low-clearance clinic. Clin J Am Soc Nephrol. 2012;7(8):1234-1241.

24. Luo J, Brunelli SM, Jensen DE, Yang A. Association between serum potassium and outcomes in patients with reduced kidney function. Clin J Am Soc Nephrol. 2016;11(1):90-100.

25. Kim Y, Evangelista LS. Relationship between illness perceptions, treatment adherence, and clinical outcomes in patients on maintenance hemodialysis. Nephrol Nurs J. 2010;37(3):271-281.

26. Chan YM, Zalilah MS, et al. Determinants of compliance behaviours among patients undergoing hemodialysis in Malaysia. PLoS One. 2012;7(8):e41362.

27. Saran R, Bragg-Gresham JL, Rayner HC, et al. Nonadherence in haemodialysis: associations with mortality, hospitalization, and practice patterns in the DOPPS. Kidney Int. 2003;64(1):254-262.

28. Kutner NG, Zhang R, McClellan WM, Cole SA. Psychosocial predictors of non-compliance in hemodialysis and peritoneal dialysis patients. Nephrol Dial Transplant. 2002;17(1):93-99.

29. Al-Khattabi GhanimHamid. Prevalence of treatment adherence among attendance at hemodialysis in Makah. Int J Med Sci Public Health. 2014;3(5):592-598.

30. Kugler C, Vlaminck H, Haverich A, Maes B. Nonadherence with diet and fluid restrictions among adults having hemodialysis. J Nurs Scholarsh. 2005;37(1):25-32

31. Kahraman A, Akdam H, Alp A, Huyut MA, Akgullu C, Balaban T. Impact of interdialytic weight gain (IDWG) on nutritional parameters, cardiovascular risk factors and quality of life in hemodialysis patients. BANTAO J. 2015;13:25-33. http://dx doi.org/10.1515/bj-2015-0006. 